\title{
Research on System Design of Government Promoting Corporate Technology Innovation
}

\author{
Chuan $\mathrm{Pu}^{*}$ \\ Thai Panyapiwat Institute of Management \\ Kunming, China \\ 28251408@qq.com
}

\author{
Lisheng Yang \\ Yunnan Nationalities University \\ Nonthaburi, Thailand \\ 28251408@qq.com
}

\begin{abstract}
In In this paper, the System Design of China Government Promoting Corporate Technology Innovation. Enterprises carry out technology innovation, government promotes it.

The empirical results show that Government policies and systems have a stake in the corporate technology innovation. Currently, the government makes institutional arrangement on enhancing strategic planning and management of technological innovation, establishing complete corporate $R \& D$ system, optimizing technological resource allocation, improving intellectual property work, boosting service innovation, promoting commercialization of research findings, elevating talent building, enhancing technological management, drive corporate innovation culture building, etc., based on which I make suggestions on further amelioration and improvement.
\end{abstract}

Keywords-corporate technology innovation; government policies; system design

\section{INTRODUCTION}

Enterprises carry out technology innovation, promote the innovation and apply innovation achievements. The corporate technology innovation has a stake in the survival and development of an enterprise, and the economic development of a region and even a country. Only the matching of technological innovation and system innovation can lead to sustainable development of technology and economy. A sustainable development can never be achieved if enterprises focus on technology regardless of the system, or emphasize system innovation in defiance of the status quo of corporate technology. The enterprises should effectively integrate technology innovation with system innovation, achieve synergies between the two, so as to make " $1+1>2$ " [5]. Therefore, research on corporate innovation based on system structure is of great value.

\section{SELECTION OF DMUS}

Corporate inclination to carry out $\mathrm{R} \& \mathrm{D}$, guide the enterprises to increase $R \& D$ investment, improve corporate innovation performance. Indirect policy support has a better effect on motivating the enterprises to increase $R \& D$ investment and innovation performance output than direct financial aid. According to the research results of Zhou Haitao
(2016) [6], government system and policy support can, to a certain extent, guide the enterprises to develop generic technology R\&D. An increase of 1 percentage point in the proportion of government $R \& D$ fund to corporate $R \& D$ expenditure will lead to an increase of 0.115 percentage points in the proportion of corporate generic technology $R \& D$ project to all the projects.

In terms of influences on corporate technology innovation, government policy subsidy has a significant positive influence on corporate $\mathrm{R} \& \mathrm{D}$ investment. In terms of influences on corporate technology innovation performance, government policy subsidy has a significant positive influence on corporate patent applications and new product output value. Therefore, we can arrive at the conclusion that government system and policy support have significant positive influence on corporate technology innovation, can motivate the enterprises to carry out $\mathrm{R} \& \mathrm{D}$ activities, guide the enterprises to increase $\mathrm{R} \& \mathrm{D}$ investment, improve corporate innovation performance.

\section{DETERMINATION OF INDICATORS}

In this paper, the following indicators are chosen based on the research results of Duan Yunlong (2012) [4], Bai Junhong (2013) [2], Zhou Haitao (2016) [6]: Total investment in R \& D, Represents the innovation costs of an enterprise; Total number of enterprise patents, Reflect the performance of enterprise innovation.Total preferential tax for R \& D Enterprises, The degree of privilege that represents the government system.Total profit: this indicator includes not only the company's income on major businesses, but also the company's income resulted from investment and the use of financing planning, which can fully reflect the company's profitability.

Based on the above analysis, this paper conducts descriptive statistics for sample indicators, the results are shown in Table 1.

\footnotetext{
* Corresponding author
} 
TABLE I. THE RESUltS OF DESCRIPTIVE STATISTICS FOR SAMPLE INPUT AND OUTPUT INDICATORS (UNIT: 10000 YUAN)

\begin{tabular}{|c|c|c|c|c|}
\hline Statistics Indicator & Maximum & Minimum & Average value & Standard deviation \\
\hline Total profit & 6079.3 & 178.7 & 2079.8 & 1101.4 \\
\hline $\begin{array}{l}\text { Total preferential tax for } R \& D \\
\text { Enterprises }\end{array}$ & 170.6 & 57.1 & 87.3 & 97.6 \\
\hline $\begin{array}{l}\text { Total investment in } R \& D \\
\text { Total number of enterprise }\end{array}$ & $\begin{array}{l}180.1 \\
11091 \text { (bit) }\end{array}$ & $\begin{array}{l}17.4 \\
19 \text { (bit) }\end{array}$ & $\begin{array}{l}88.1 . \\
276 \text { (bit) }\end{array}$ & $\begin{array}{l}99.5 \\
456(\text { bit })\end{array}$ \\
\hline
\end{tabular}

\section{DEA RESUlts}

According to my collection and classification, Chinese government promotes corporate technology innovation in following ways at present:

\section{A. Strengthen strategic planning and management on} technology innovation.

The government scientifically compiles strategic planning on technology innovation, takes technology innovation as the core strategy of transformation and development, conducts top-down design and overall planning, highlights the main work, clarifies the development path of technology innovation, determines the objectives, direction and tasks. It enhances researches on industrial technology, determines key special and prioritized technology projects, focuses on planning a batch of key technological transformation and technology innovation projects with high degree of industrial relations, high technology content, promising market prospects, organizes, implements, tracks and evaluates technology planning. It promotes the traditional advantageous industries to articulate with world-class enterprises, formulates and implements building program of innovative enterprise.

\section{B. Establish complete corporate $R \& D$ systems.}

The government establishes the R\&D system suitable for the corporate development, clarifies the duty and positioning of group, branch and grass-roots $R \& D$ departments in innovation chain, forms echelon structure matching technology with technology development, application research, basic research. It encourages and supports the establishment of new model of corporate leadership, institution-university collaboration, diversified investment, military-civilian integration and achievement sharing, guides the enterprises to speed up the building of various R\&D centers such as key laboratories and engineering and technology research centers, develops research cooperation. It speeds up the construction of industrial public technology R\&D center, provides support to effectively solve key generic technology problems in the chain link. It strengthens the construction of corporate internal R\&D institutions and scientific research infrastructure, improves R\&D test methods. It also actively explores efficient and smooth R\&D operation mechanism to drive dynamic combination of R\&D, design, engineering and production, and promote the transformation of scientific research to productivity.

\section{Optimizing technology resource allocation.}

The government further enhances the optimal allocation, efficient utilization and opening \& sharing of corporate technology resources, realizes dynamic integration of internal and external resources. It increases the integration of internal technology resources, solves the problems such as distributed corporate technology resources, overlapped classification and repeated technology development, improves innovation chain, and achieves effective coordination of technology strength. It actively makes use of external technology resources, obtains innovation resources through cooperation, commission, merger and acquisitions, etc. It actively explores the construction of overseas R\&D institutions and develops international $R \& D$ cooperation.

\section{Improve intellectual property work.}

The government formulates and implements corporate intellectual property strategy, improves the operation mode and working mechanism of intellectual property management, and enhances the creation, application, management and protection of intellectual property. It promotes the rapid growth of the patent number, increases the proportion of invention patents, and makes achievement of core patents and independent intellectual property rights in the leading industries and key technologies. It establishes the information retrieval, infringement early-warning and risk prevention system of intellectual property, explores the establishment of "patent pool". It strengthens the application of intellectual property results, improves its capitalization. It also formulates intellectual property protection measures, strengthens internal management, prevents the leakage of corporate business secretes and core technologies.

\section{E. Support the research and formulation of technical standards.}

The government gives full play to corporate standard work foundation, promotes benign interaction between technology innovation and standard work. It supports enterprises with innovative achievements to carry out the research and formulation of standards, promotes the commercialization, application and popularization of innovative achievements. It promotes the technologies with independent intellectual property to be upgraded to technology standards to play a better role in the formulation of national standards and industry standards. It supports standard R\&D, assessment and test of corporate intellectual property, promotes more technology standards to be domestic and 
international standards, and strengthens the presence of enterprises in the field of standards [2].

\section{F. Speed up open cooperation and innovation.}

The government strengthens the combination of production, teaching and research, establishes the long-term mechanism of cooperation, and promotes the healthy development of industrial technology innovation strategic alliance. It enhances innovative cooperation among enterprises and industry chain, forms an open cooperation mechanism with complementary advantages, clear division of work, results sharing and risk-sharing. It supports the enterprises to conduct international cooperation through joint venture, mergers and acquisitions, joint $\mathrm{R} \& \mathrm{D}$, builds international cooperation base in the key field of industrial technology innovation, promotes corporate technology innovation and industry structure optimization, and enhances corporate international competitiveness. It also encourages the corporate technical personnel and managerial staff to participate in international exchange for innovation and cooperation.

\section{G. Boost service innovation}

The government establishes technical supporting system for service innovation. Guided by customer demands, it integrates advanced technology in various fields, carries out business model innovation, and improves market resilience. It integrates the technology innovation and service innovation of manufacturing enterprises, realizes the transformation from product manufacturing to system design integration and overall solutions, and enhances the rapid development of production-related service industry. It expedites the innovation of service products and service modes, improves the overall supporting capabilities of R\&D, information, logistics, etc.

\section{H. Promote the commercialization of technology achievements.}

The government establishes the technology innovation achievement commercialization mechanism dominated by enterprises, supports technology achievement commercialization bases co-built by enterprises, research institutes and universities, and realizes the industrialization of major technology achievements. It boosts the commercialization of intellectual property results and development of new products. Based on existing enterprises and industrial base, prioritized by the development of new products, it dynamically combines resource advantages and industry chain extension, promotes the development of new technologies, products and formats, upgrades the industry, products, management, brands and commercial modes. It encourages the enterprises to purchase major technology achievements, attracts high-level domestic and international R\&D institutions, technology enterprises, talents and teams to embark on innovation R\&D and achievement commercialization

\section{Improve talent building.}

The government implements the strategy of "talents prosper enterprises", builds technology talent teams with proper structure, excellent quality and innovation spirit. It improves the evaluation, selection, training, application and incentive mechanism of technology talents, manages technology talents and managerial staff separately and strengthens technical service system of technology talents, enhances the training of young technology talents and highly skilled talents. Through implementation of major technology projects and cooperation of production, teaching and research, it trains a batch of leading technology talents and innovation teams with top industrial development level. It increases the incentives for technology talents, grants special rewards for the technology talents with outstanding contributions, builds corporate innovation and entrepreneurship bases to attract high-level technology talents at home and abroad.

\section{J. Further improve technology management.}

The government improves technology management system, work process, efficiency and level of technology management. It enhances the basic work of statistical investigation and analysis on corporate technology, technical file management, technology information, knowledge management, etc. It grasps innovation direction, makes technology management more forward-looking and targeted, strengthens research on innovation model and methods, improves innovation efficiency, enhances the establishment and management of corporate technology innovative information platform, promotes the cooperation and sharing of technology information resources among enterprises.

\section{K. Promote the construction of corporate innovation culture.}

The government actively carries out the construction of mass innovation culture, encourages mass technology innovation and technology invention, mobilizes the enthusiasm of mass workers, and pool resources to solve the technical problems in production. It encourages the spirit of innovation, competition, honest cooperation and tolerance of failure, creates a cultural atmosphere of respect for knowledge, talents, labor and creation. It takes encouraging innovation as the important content for corporate cultural building, promotes the pioneering spirit of entrepreneurs, trains the R\&D workers to conduct painstaking research with a dedicated spirit, and arouses innovative enthusiasm and vigor of technology workers.

The efficiency and returns to scale of Chinese Corporate Technology Innovation nature in 2016 are from Research on System Design the angle of input according to the formula, the calculation results are shown in Table 2. 
The difference System Design of Government Promoting to CALCULATiOn RESUlts OF EFficiency and Returns to Scale of YUNNAN CORPORATE TECHNOLOGY INNOVATION NATURE IN 2016

\begin{tabular}{|c|c|c|c|c|c|c|c|c|c|}
\hline Item & CRS & VRS & VRS & $\bar{\Lambda}$ & Item & CRS & VRS & VRS & $\bar{\lambda}$ \\
\hline$I V A$ & 1 & 1 & 0.99 & + & $I V G$ & 1 & 1 & 0.97 & + \\
\hline$I V B$ & 1 & 1 & 0.99 & + & $I V H$ & 1 & 1 & 1 & 0 \\
\hline$I V C$ & 1 & 0.99 & 0.97 & + & $I V I$ & 0.95 & 1 & 0.97 & + \\
\hline$I V D$ & 1 & 1 & 0.97 & + & $I V J$ & 1 & 1 & 1 & 0 \\
\hline$I V E$ & 1 & 1 & 1 & + & $I V K$ & 0.97 & 0.98 & 0.98 & + \\
\hline$I V F$ & 1 & 1 & 0.98 & + & & & & & \\
\hline
\end{tabular}

Note: VRS, CRS, SC refer to pure Technology Innovation efficiency, Technology Innovation efficiency, scale efficiency and returns to scale respectively; + progressive increase; - progressive decrease; 0 invarian.

\section{Analysis of overall Technology Innovation efficiency}

The mean of overall Technology Innovation efficiency of calculation results of efficiency and returns to scale of yunnan corporate technology innovation nature in 2016 is 0.96 , the minimum overall efficiency value is 0.91 .

The he overall Technology Innovation efficiency of 9 System Design reaches 1, indicating that such companies have quite reasonable input and output of resources, effective scale \& technology and constant returns to scale, the industry completely achieves all benefits brought about by scale efficiency and technical efficiency, and there is no loss of efficiency.

\section{Analysis of pure Technology Innovation efficiency}

In this study, the mean of sample pure technical efficiency is 0.99 , among them, the pure technical efficiency value of 9 System Design is greater than or equals to the mean, however, the overall level is still low.

\section{$N$. Analysis of scale efficiency}

In this study, 11 System Design are above the mean of 0.97 , indicating that the overall scale efficiency of such companies is relatively high.

\section{CONClusions AND SUGgestions}

The government carries out system and policy design on promoting corporate innovation and technology innovation, but how to put them into practice and make the system meet the corporate demands? I think following security mechanisms are indispensable.

(1) Strengthen organization and leadership. The relevant government departments should establish consultation mechanism of corporate technology innovation, guide and coordinate overall deployment, major problems and major issues of technological innovation in the domain. The enterprises carry out the technological innovation decisionmaking, R\&D investment, scientific research organization and result commercialization, so enterprises should put technology innovation on the top agenda of corporate reform and development, enhances and ameliorates the organization and leadership of technology innovation. The corporate leadership should include the technology into the top agenda, special leaders should be assigned to technology innovation work with a clear division of labor and implementation of leadership responsibility.[4] The technology, planning, investment, finance, human resources and other departments should strengthen coordination and collaboration, adopt effective measures, implement responsibilities to jointly promote the implementation of key scientific research tasks.

(2) Improve organization and management institutions. The enterprises should enhance construction of technology management and organization institution with implemented institutions and sound systems. Based on the needs of corporate technology innovation, special technology management departments should be established to clarify job positioning. The professional management advantages of technology departments should be made use of to strengthen unified management and improve group technology control. The technology decision-making should be more scientific and procedural, technology decisionmaking and advisory institutions such as scientific and technological committees and expert advisory committees can be set up as needed. The board of directors should employ external directors familiar with technology.

(3) Improve the system and mechanism of technology innovation. The enterprises should reinforce reform, enhance system and mechanism innovation. They should establish long-term mechanism for steady growth of technology investment, ensure that the corporate $R \& D$ investment increases along with the operation revenue. They should include the technology investment into overall budget management, establish special fund system for technology development, improve technology assessment index system, explore to include the application and commercialization of major technology achievements into the performance assessment of related corporate leaders, establish the mid-and long-term incentive mechanism for backbone technology workers, implement the system of participating in distribution based on contribution for major production performance such as management and technology. If possible, the enterprises should carry out incentive pilot such as equity, options and dividends. They should improve technology evaluation and reward system, establish technology reward special fund to reward advancing units and individuals with outstanding contributions. 
(4) Expand technology investment channels. The enterprises should invest on innovation, and try to win the financial support from the national and local governments after ensuring the stable and sustainable growth of corporate R\&D [3]. They should enhance the cooperation between technology and finance, actively articulate the financial capital, venture capital and technology achievements, raise technology investment funds by utilizing venture capital funds, corporate bonds, insurance funds and private equity funds, etc., innovate the mechanism and system of technology investment, optimize project operation, promote the technology enterprises to introduce private investment, foreign investment and other strategic investment, or raise funds in domestic and foreign capital markets.

(5) Enhance policy support. The government should implement national and local policies on improving corporate technology innovation, guide and support the enterprises to undertake various technology plans, organize and implement major technology projects. It should subsidize enterprises purchasing technology SMEs with R\&D teams and technology achievements; give full financial support to physical industry technology research institutes focusing on industrial technology innovation needs; proportionally subsidize the enterprises choosing projects based on market demands and developing together with universities and institutions for the $R \& D$ expenditure paid to universities, research institutes, etc.; grant financial support to enterprises enhancing R\&D institution construction, developing new products, implementing technology achievement commercialization and industrialization, promoting talent building, etc. The government should earnestly implement additional deduction of $\mathrm{R} \& \mathrm{D}$ expenditure, tax breaks for hi-tech enterprises, accelerated depreciation of fixed assets, etc., to encourage the enterprises to increase R\&D expenditure.

\section{ACKNOWLEDGMENT}

This paper, The first person to thank and be grateful is my mentor, professor Duan Yunlong at Yunnan University of Finance and Economics. In the writing of the conference paper, I have learned a lot from the first draft, from the revision, to the style of writing and the style of writing.In addition, I also want to thank the leadership and comrades of Thailand's $\mathrm{cp}$ management institute for their help and care during my PhD. Thank you for your support! Kindly say thank you to help them! The paper was supported by National Natural Science Foundation of China(71663058), (71663062), (71262016)

\section{REFERENCES}

[1] T.L. An, "Technical Choice of Chinese Enterprises," Economic Research, vol. 7, 2003.

[2] J.H. Bai, and R.X. Li, "Review and Research on Government R\&D Financing Corporate Technology Innovation," Chinese Technology Forum, vol. 9, 2013.

[3] J. Chen, "Research and Development Management," Beijing: Tsinghua University Press, 2009.

[4] Y.L. Duan, "Mechanism Research on System Structure Function of Corporate Sustainable Technology Innovation," Kunming University of Science and Technology, 2008.

[5] Y.L. Duan, "Evaluation and Application of Corporate Sustainable Technology Innovation Capability Based on System Structure," Statistics and Decision-making, vol. 5, 2010.

[6] H.T. Zhou, "Research on the Impact of Government R\&D Fundingon Enterprises' Technological Innovation Decision - making, Behavior and Performance - - Based on Micro PanelData of High-tech Enterprises," South China University of Technology, 2016. 